\title{
Incorporating Experience Curves in Appliance Standards Analysis
}

Louis-Benoit Desroches, Karina Garbesi, Colleen Kantner, Robert Van Buskirk, Hung-Chia Yang.

\author{
Environmental Energy Technologies Division \\ Lawrence Berkeley National Laboratory \\ 1 Cyclotron Road, Berkeley, CA 94720
}

Sept. 4, 2012

This work was supported by the U.S. Department of Energy, Office of Energy Efficiency and Renewable Energy, Building Technologies Program under Contract No. DE-AC02-05CH11231 


\section{Disclaimer}

This document was prepared as an account of work sponsored by the United States Government. While this document is believed to contain correct information, neither the United States Government nor any agency thereof, nor the Regents of the University of California, nor any of their employees, makes any warranty, express or implied, or assumes any legal responsibility for the accuracy, completeness, or usefulness of any information, apparatus, product, or process disclosed, or represents that its use would not infringe privately owned rights. Reference herein to any specific commercial product, process, or service by its trade name, trademark, manufacturer, or otherwise, does not necessarily constitute or imply its endorsement, recommendation, or favoring by the United States Government or any agency thereof, or the Regents of the University of California. The views and opinions of authors expressed herein do not necessarily state or reflect those of the United States Government or any agency thereof or the Regents of the University of California.

Lawrence Berkeley National Laboratory is an equal opportunity employer. 


\title{
Incorporating Experience Curves in Appliance Standards Analysis
}

\author{
Louis-Benoit Desroches*, Karina Garbesi, Colleen Kantner, Robert Van Buskirk, \\ Hung-Chia Yang \\ Environmental Energy Technologies Division, Lawrence Berkeley National Laboratory, 1 Cyclotron Road, \\ Berkeley, CA 94720, USA
}

\begin{abstract}
There exists considerable evidence that manufacturing costs and consumer prices of residential appliances have decreased in real terms over the last several decades. This phenomenon is generally attributable to manufacturing efficiency gained with cumulative experience producing a certain good, and is modeled by an empirical experience curve. The technical analyses conducted in support of U.S. energy conservation standards for residential appliances and commercial equipment have, until recently, assumed that manufacturing costs and retail prices remain constant during the projected 30-year analysis period. This assumption does not reflect real market price dynamics. Using price data from the Bureau of Labor Statistics, we present U.S. experience curves for room air conditioners, clothes dryers, central air conditioners, furnaces, and refrigerators and freezers. These experience curves were incorporated into recent energy conservation standards analyses for these products. Including experience curves increases the national consumer net present value of potential standard levels. In some cases a potential standard level exhibits a net benefit when considering experience, whereas without experience it exhibits a net cost. These results imply that past energy conservation standards analyses without experience curves may have undervalued the economic benefits of potential standard levels, possibly resulting in less stringent standards and reduced energy savings than was economically justified.
\end{abstract}

Keywords: Efficiency standards, Experience curves, Large appliances

\section{Introduction}

The U.S. Department of Energy (DOE) develops energy conservation standards for residential appliances and commercial equipment. ${ }^{1}$ Improved energy efficiency is generally assumed to increase initial purchase costs, but decrease operating costs. In support of any new proposed standard, DOE conducts an analysis of the consumer

\footnotetext{
*Corresponding author. Tel: +1510 486 5833

Email address: 1desroches@lbl .gov (Louis-Benoit Desroches)

${ }^{1}$ http://www1.eere.energy.gov/buildings/appliance_standards/
} 
life-cycle costs (LCC) and savings of a given product meeting the new standard, in addition to a national impact analysis (NIA) that calculates the economic and energysavings impact on the nation over a 30-year time period. An important input to these calculations is the engineering analysis, which determines the incremental appliance purchase cost as a function of incremental energy efficiency improvement. As codified in the statute, standards may be promulgated if and only if they are shown to be technically feasible and economically justified. To date, these analyses have assumed that the manufacturing costs and retail prices of appliances and commercial equipment (hereafter referred to generally as "appliances") are fixed during the typical 30-year analysis period.

There is, however, significant historical evidence of consistent declines in appliance prices, which implies that DOE's appliance standards analysis may be undervaluing the economic benefits to society. Dale et al. (2009) have noted that U.S. appliance efficiency regulation does not address trends in real market prices and energy efficiency improvements. They studied historical price trends of room air conditioners (AC), central AC, refrigerators, and clothes washers, and had four major findings: (1) for the past several decades, the retail price of appliances has been steadily falling while efficiency has been increasing; (2) past retail price predictions made in the analyses of efficiency standards, assuming constant prices over time, have tended to overestimate retail prices; (3) the average incremental price to increase appliance efficiency has declined over time, and the analyses of efficiency standards have typically overestimated this incremental price and retail prices; and (4) changes in retail markups and economies of scale in production of more efficient appliances may have contributed to declines in prices of efficient appliances. This problem of not addressing real market prices is not limited to the U.S. Appliance standards and labeling programs in Australia, Japan, and Europe suffer from similar overestimations of the cost of increased efficiency (Ellis et al., 2007).

There is an extensive literature, applicable to a broad range of applications and industries, documenting how real production costs and prices of goods tend to fall in a relatively predictable way as cumulative production increases. This phenomenon is generally referred to as learning or experience. Wright (1936) pioneered the concept when studying the falling unit cost of aircraft production (a topic revisited by Alchian, 1963). Early applications continued to focus on manufacturing (Hirsh, 1952; Arrow, 1962), but since then the concept has been widely applied to such diverse products and services as semiconductors (Gruber, 1992), building envelopes (Jakob \& Madlener, 2004), nuclear reactors (Joskow \& Rozanski, 1979; Zimmerman, 1982), liquefied natural gas (Greaker \& Sagen, 2008), solar photovoltaics (Masini \& Frankl, 2002; van der Zwaan \& Rabl, 2003; Nemet, 2006; van Benthem et al., 2008), wind power (Ibenholt, 2002; Junginger et al., 2005; Klaassen et al., 2005), renewable energy technologies (Neij, 1997; Papineau, 2006), energy generation technologies (Jamasb, 2007), and electric utility investments (Laitner \& Sanstad, 2004). Management consulting firms have studied experience for a diverse set of clients and products (e.g., BCG, 1972, 1980). To date, however, the study of experience for appliances and commercial equipment has been limited (Bass, 1980; Newell, 2000; Laitner \& Sanstad, 2004; Jardot et al., 2009; Weiss et al., 2010a,b). A thorough review of the extensive historical work on learning and experience, across many disciplines, is provided by Fusfeld (1973), Yelle (1979), 
Day \& Montgomery (1983), Dutton \& Thomas (1984), Argote \& Epple (1990), Newell (2000), IEA (2000), McDonald \& Schrattenholzer (2001), and Weiss et al. (2010a) (and references therein). In addition, Baumol (1967) and Baumol et al. (1985) established the framework of unbalanced growth in the economy, explaining why certain sectors of the economy may have distinct real price trends from other sectors.

The empirical phenomenon of falling prices is typically modeled by a learning curve or an experience curve, depending on the scope of the analysis and the nature and breadth of causal factors. Learning and experience curves are functions relating the cost of production to quantity produced (typically cumulative production). Learning curve analysis tends to focus more narrowly on relatively well-characterized and localized factors of production that result in price reductions of a single standardized product (e.g., learning by workers and management that reduces labor hours needed for production), while experience curve analysis focuses on entire industries (often operating globally) and aggregates over many causal factors that may not be well characterized. The two main causal factors typically associated with learning curves are labor-based learning and investment in new capital equipment (Dutton \& Thomas, 1984). In its broadest sense, however, experience curve analysis implicitly includes factors such as efficiencies in labor, capital investment, automation, materials prices, and distribution at an industry-wide level (Newell, 2000). Since market competition is very effective, learning in one plant or firm rapidly diffuses to other firms as well, leading to industrywide effects. Learning and experience curves have been empirically demonstrated at both the microeconomic and macroeconomic levels. It should be noted, however, that the literature seldom distinguishes between the use of these two terms, and they are often used interchangeably.

Various studies have examined the conditions under which experience (and learning) curve analysis could be used in support of policy to escalate commercialization of emerging technologies, and as a mechanism of assessment (IEA, 2000; Neij et al., 2003; van Benthem et al., 2008; Jamasb \& Köhler, 2008; Ferioli et al., 2009). Experience is already incorporated into the Energy Information Administration's (EIA) National Energy Modeling System (NEMS; Newell, 2000), a model that is utilized for energy policy analysis. Some previous studies of energy-saving potentials achievable through standards have included modest experience parameters (e.g., Rosenquist et al., 2006).

There is therefore a potential bias in past estimates of the cost of efficiency for appliances. However, experience curves have recently been incorporated into the analysis of energy conservation standards for residential clothes dryers, room air conditioners, central air conditioners and heat pumps, furnaces, refrigerators and freezers (US Department of Energy, 2011a,b,c). In this paper, we describe how those experience curves were determined and how the standards analysis was modified to include them (Section 2 ), calculate the appropriate experience rates and the effects on the national net present value for these appliances (Section 3), and provide some discussion on the methodology and considerations for future analyses (Section 4). Finally, we summarize our results (Section 5). 


\section{Methodology and Data Sources}

This section describes the methodology and data sources used to determine the experience curve and experience rates for recent DOE energy conservation standards. In addition, we describe how experience rates were incorporated into the existing analysis framework. For more details on data sources and methods used to determine experience, as well as a full description of the appliance standards analysis process, see the energy conservation standards Technical Support Documents (TSD; US Department of Energy, 2011a,b,c).

\subsection{Experience Curves}

The conventional functional relationship for both learning and experience is given by

$$
P(X)=P_{o}\left(\frac{X}{X_{o}}\right)^{-b},
$$

where $P_{o}$ is an initial price (or cost), $b$ is a constant known as the experience rate parameter, $X_{o}$ is the initial cumulative production, $X$ is cumulative production, and $P$ is the price as a function of cumulative production. The experience rate is defined as the fractional reduction in price/cost that results from each doubling in cumulative production,

$$
E R=1-2^{-b} .
$$

For example, an experience rate of 0.25 implies a $25 \%$ cost reduction for each doubling of cumulative production.

Cumulative production is generally considered to be an appropriate proxy for knowledge accumulated. Production-driven models are generally better predictors of learning and experience effects than time-driven models (Newell, 2000; Bailey et al., 2012), since production-driven models implicitly account for variations in production resulting from macroeconomic conditions such as recessions. Despite these advantages, however, it is important to remember that cumulative production is a proxy measure for the underlying (and related) causal factors. Furthermore, learning and experience curves are empirical relationships, though they are readily accepted due to the strength and robustness of the empirical evidence.

The final experience curves were obtained from a linear regression in log-log space as opposed to real space. This is reasonable if we assume: (1) the true errors in the price index are proportional to the value of the index; and (2) the errors are relatively small so that asymmetries in log space are minimal.

\subsection{Product Prices}

Direct manufacturing costs are very difficult to obtain, as these data are often proprietary. As a proxy for manufacturing costs, we use price indices from the Bureau of Labor Statistics (BLS), in particular the Producer Price Index (PPI). ${ }^{2}$ The PPI is an indicator of wholesale distributor price, adjusted for quality changes over time, and

\footnotetext{
${ }^{2}$ http://www.bls.gov/ppi/
} 
Table 1: Producer Price Indices utilized for the experience curve analysis, available from the Bureau of Labor Statistics.

\begin{tabular}{|c|c|c|c|}
\hline Appliance & Series Name & Price Index Series ID & Series Interval \\
\hline Central air conditioners & $\begin{array}{l}\text { Unitary air-conditioners, except air source heat } \\
\text { pumps }\end{array}$ & PCU333415333415E & $1978-2010$ \\
\hline Clothes dryers and washers & $\begin{array}{l}\text { Household laundry equipment manufacturing - } \\
\text { Primary products }\end{array}$ & PCU335224335224P & $1980-2010^{a}$ \\
\hline Furnaces & $\begin{array}{l}\text { Warm air furnaces, incl. duct furnaces \& humidi- } \\
\text { fiers, \& electric comfort heating }\end{array}$ & PCU333415333415C & $1990-2010$ \\
\hline \multirow[t]{2}{*}{ Refrigerators and freezers } & Household refrigerator and home freezer mfg & PCU335222335222 & $1977-2010$ \\
\hline & Refrigerators and home freezers & MWUR0000SE3001 ${ }^{b}$ & $1947-1997$ \\
\hline Room air conditioners & $\begin{array}{l}\text { Room air-conditioners and dehumidifiers, except } \\
\text { portable dehumidifiers }\end{array}$ & PCU3334153334156 & 1990-2009 \\
\hline
\end{tabular}


Table 2: Time intervals for appliance shipment data. Data are from industry trade associations such as AHAM, GAMA, AHRI, and Appliance Magazine.

\begin{tabular}{lcc}
\hline Appliance & Annual Shipments & Decadal Shipments \\
\hline Central air conditioners & $1953-2009$ & \\
Clothes dryers & $1946-2009$ & \\
Clothes washers & $1972-2008$ & $1940-1979$ \\
Furnaces & $1953-2009$ & \\
Refrigerators and freezers & & \\
$\quad$ Standard size refrigerators & $1930-2008$ & \\
Standard size freezers & $1946-2007$ & \\
Compact refrigerators & $1983-2007$ & \\
Compact freezers & $1983-2007$ & \\
Room air conditioners & $1946-2009$ & \\
\hline
\end{tabular}

is available for a wide variety of specific industries (e.g., refrigerator manufacturing) organized by the North American Industry Classification System (NAICS) code. Since we are only interested in changes in producer prices and not in absolute prices, the indices, once inflation-adjusted, are suitable for the analysis. Annually averaged PPI data were adjusted for inflation using the Consumer Price Index - All Items Index ${ }^{3}$, a broad indicator of inflation in the economy. ${ }^{4}$ Table 1 summarizes the PPI series used in the subsequent analysis. The household laundry equipment series was assumed to represent both clothes dryers and clothes washers because more detailed data were unavailable. A PPI series is available for heat pumps, but includes only a few years of data. As a result, the experience curve for heat pumps was assumed to be the same as for central air conditioners.

In the special case of refrigerators and freezers, a second discontinued price index exists from 1947-1997 as part of the Consumer Price Index (such a series does not exist for other home appliances). Given the important leverage that 30 extra years of data can provide, the discontinued CPI series and the PPI series for refrigerators were combined to form a unified price index. The years of overlap (1977-1997) for refrigerator and freezer data were examined for differences, and a regression was performed to allow normalization of the PPI data to the CPI data. 


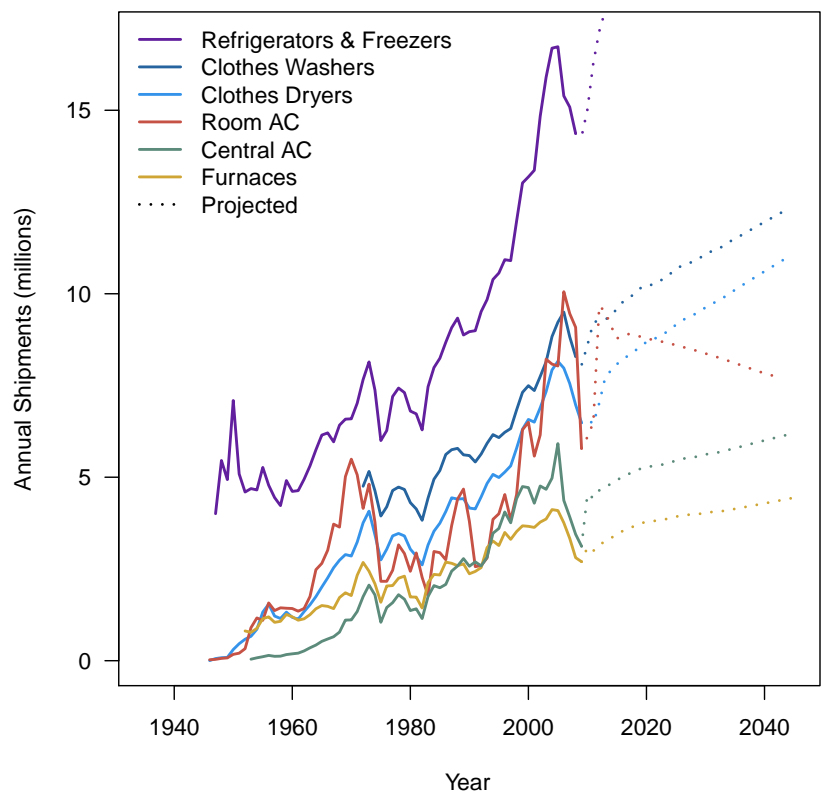

Figure 1: Annual shipments for clothes dryers, clothes washers, room air conditioners, central air conditioners, furnaces, and refrigerators and freezers (US Department of Energy, 2011a,b,c). Dotted lines are projected shipments. Refrigerator and freezer shipments combined are projected to reach 30 million units by 2043. 


\subsection{Cumulative Production}

Annual shipment data were provided as part of the energy conservation standard rulemaking process by several industry trade associations, including the Association of Home Appliance Manufacturers (AHAM), Gas Appliance Manufacturers Association (GAMA), and the Air-conditioning, Heating, and Refrigeration Institute (AHRI). Annual shipment data were also available from publications such as Appliance Magazine and the AHAM Fact Book. In most cases, the data exist all the way back to the first year of production. For furnaces, shipments prior to 1953 were extrapolated backward based on a linear trend to the historical shipments (back to 1937). For compact freezers, an exponential fit was used to extrapolate back to 1951. In some cases, decadal shipments are available from the first decade of production onward, and were used when annual shipment data from the first year of production were not available. Projected shipments, used to project the experience curves to future years, were obtained from the base case projections in the energy conservation standards analyses. See Fig. 1 and Table 2 for a summary of the annual shipments used. The annual shipments data were then used to calculate cumulative production.

\subsection{Amending Appliance Standards Analyses}

The analyses performed in support of federal appliance energy conservation standards rulemakings include a consumer life-cycle cost analysis (for the first year of compliance) and 30-year cumulative national impacts analysis. Both sets of analyses consider various trial standard levels (TSLs), which are potential new energy conservation standards above the current minimum standard. The convention is to name TSL 1 the lowest potential new standard, TSL 2 the next lowest, and so on.

Both the LCC and NIA analyses rely on an engineering analysis that establishes the incremental cost of improved efficiency for each appliance. The main engineering analysis outputs are cost-efficiency curves (relationships of the increase in cost for a given increase in efficiency). These costs are then marked up to include manufacturer and retailer margins, resulting in final consumer prices. These final prices as a function of efficiency are main inputs into the LCC and NIA analyses.

The LCC analysis uses Monte Carlo simulations to determine the distribution of consumer impacts for various TSLs, in the first year of compliance. For each TSL, the LCC indicates what percentage of current consumers would experience a positive economic impact, negative impact, or no impact if they replaced their current appliance with new standards in place. The LCC considers both the initial purchase price and the life-cycle operating costs. LCC inputs include distributions of households (e.g.,

\footnotetext{
${ }^{3}$ http://www.bls.gov/cpi/

${ }^{4}$ For refrigerators and freezers, the methodology was adjusted such that the Chained GDP Price Index (http://www.gpoaccess.gov/usbudget/fy11/hist.html) was used to correct for inflation (US Department of Energy, 2011c). This was done to better align with the electricity price forecasts used in the model, which are deflated using a projected Chained GDP Price Index. There is an approximately $0.3 \%$ per year cumulative difference in the inflation adjustment between the two indices (e.g., for 1980, this corresponds to an approximately $10 \%$ difference in inflation adjustment to 2010 dollars). The CPI index is the larger correction factor. The results presented here for refrigerators and freezers use the Chained GDP Price Index.
} 
with varying size and location), usage patterns, equipment lifetimes, energy prices, and discount rates.

The NIA models the aggregate impacts across the nation over 30 years, using a forecast for annual shipments, average energy prices, and baseline improvements in efficiency. The NIA includes monetized values for emissions reduction $\left(\mathrm{CO}_{2}\right.$ and $\left.\mathrm{NO}_{\mathrm{X}}\right)$. Key outputs of the NIA are the total energy savings (in quadrillion Btu) and the net present value (NPV) of those savings, for each TSL (see Fig. 2 for an illustrative NIA result). The NPV is the discounted sum of total costs and savings over the 30-year period, discounted to the year of the analysis. Based on these results, the Secretary of Energy then determines which TSL will become the next federal appliance standard, weighing a number of factors (e.g., energy savings, consumer impacts, manufacturer impacts). Ultimately, the chosen standard should achieve significant energy (and water) savings, while being technologically feasible and economically justified. ${ }^{5}$

Incorporating experience curves into the LCC analysis portion of the appliance energy conservation standard analysis is straightforward. The LCC is only calculated for the first year of compliance, and the compliance year is typically 3-5 years after publication of a Final Rule by DOE. Thus, the input prices that are fed into the LCC model are simply deflated by a single value, representing the experience gained between the date of the engineering analysis in support of the rulemaking to the first year of compliance. For the national impact analysis, the average purchase prices (in real dollars) for all efficiency levels are deflated each year in the 30-year analysis, much like the electricity prices are adjusted every year. Thus, appliances purchased late in the 30-year analysis period are less expensive in real dollars than those purchased in the first year of compliance.

This approach, while straightforward, assumes that the baseline price and the incremental price of efficiency are both deflating at the same rate (with the same experience parameters). This assumption may not be strictly true in reality, as efficient technologies may not be as mature as baseline technologies. As discussed below in Section 4.6, however, we argue that this assumption leads to a conservative estimate of the experience effects.

\subsection{Sensitivity Scenarios}

Forecasting price indices over a 30-year period can be potentially very sensitive to uncertainties in fitting an experience curve (van Sark, 2008; Yeh et al., 2009). To better understand how uncertainty in the experience curve analysis might affect the policy choice determined from the energy conservation standard analysis, several experience rate sensitivity scenarios were calculated. A few alternative (non-experience curve) price trend models were also explored as sensitivity scenarios.

To determine if the experience rate parameter changes as a function of time, due to long-term structural changes in a particular industry, we performed experience curve fits on two or more component periods in the historical data (roughly splitting the time series in half). For several appliances, the year splitting the two components was chosen to be the compliance year for the first federal energy conservation standard for

\footnotetext{
${ }^{5}$ These criteria for prescribing new standards are required by statute. See 42 U.S.C. $6295(0)(2)$.
} 


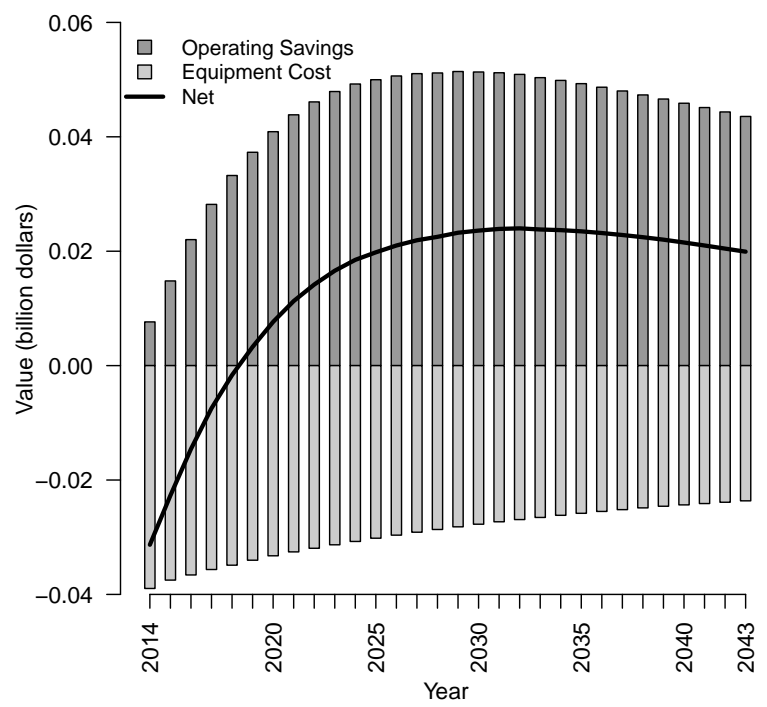

Figure 2: Illustrative example of results from a NIA. Shown are the undiscounted annual operating savings and initial purchase cost increases for a hypothetical appliance at a hypothetical trial standard level, as well as the net benefit or cost. Because the results are aggregated over the nation, each year a new set of consumers purchases replacement appliances (hence why the savings rise quickly initially). Each appliance also has a lifetime of many years, so that operating savings are propagated for several years. The savings begin to decline at the end of the analysis period since the model assumes a baseline improvement in efficiency occurs whether or not a new standard is implemented. Total purchase costs decrease as a result of experience (though the effect is counter-balanced by increased shipments). The NPV would be the discounted sum of the net benefit/cost over the 30 year analysis period. 


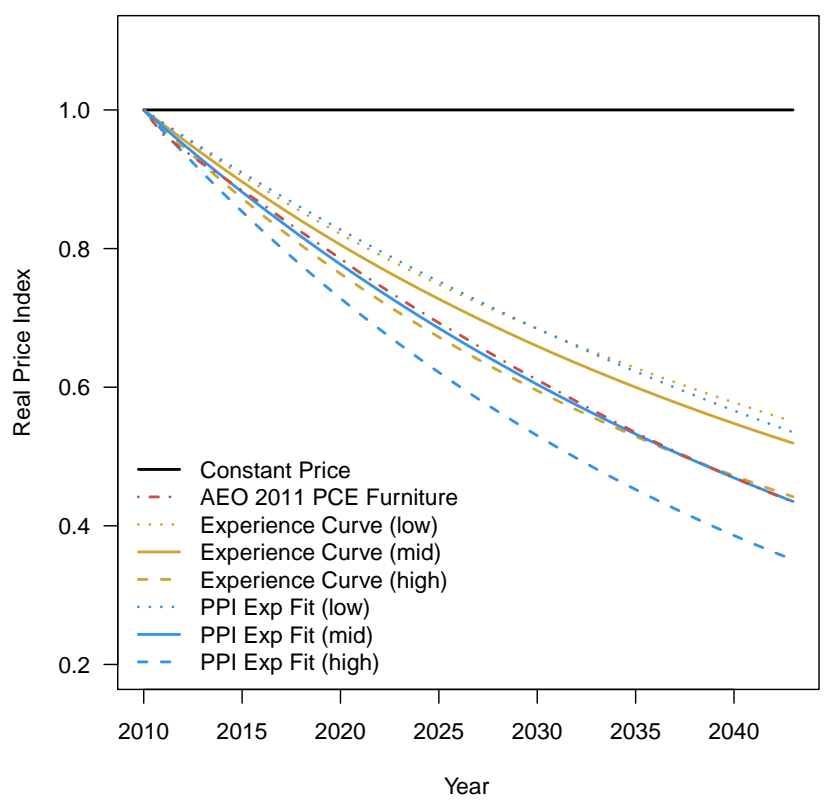

Figure 3: Illustration of the various sensitivity scenarios for the case of residential refrigerators and freezers. Included are the experience curve, the exponential model, and the price trend from AEO2011. All scenarios are normalized such that the price index in 2010 equals 1 . Prior analyses assumed a constant price. 
that product. For refrigerators, several fits were performed to various CPI and PPI subseries.

In the clothes dryer case, the PPI series that was used represented a more aggregate product category than the appliance analyzed (e.g., household laundry equipment vs. clothes dryers or washers). In this instance, an additional sensitivity scenario was calculated. Price data were collected from Consumer Reports and market research firms such as NPD on clothes dryers and clothes washers. Using these data, an experience rate was calculated for clothes dryers only, using cumulative shipments for that appliance only. Although this experience rate is more representative than the rate based on the aggregate PPI category, the clothes dryer price data cover only a handful of years. As a result, the fit is not nearly as robust as that based on the PPI of the aggregate category.

In the case of refrigerators and freezers, we also considered an alternative exponential model (e.g., similar to Moore's law; Moore, 1965) to extrapolate the price trend. An exponential model uses time as an explanatory variable, instead of cumulative shipments. If annual (and cumulative) shipments are exponential with time, the experience curve and the exponential model are equivalent:

$$
P=P_{o}\left(\frac{X}{X_{o}}\right)^{-b}=P_{o}\left(\frac{X_{o} e^{a t}}{X_{o}}\right)^{-b}=P_{o} e^{-\alpha t},
$$

where $P$ is the price, $P_{o}$ is the initial price, $t$ is the time variable which equals the year difference between the base year and any given year, and $\alpha$ is the exponential parameter of the time variable. This model can be alternatively expressed as a percentage decline/increase in price per year. Although time-driven models are generally not as accurate as production-driven models (based on hindcast studies; e.g., Bailey et al., 2012), several recent studies of technological progress have utilized them (Koh \& Magee, 2006, 2008), so we considered them here for completeness.

EIA uses the NEMS model when publishing their Annual Energy Outlooks (AEO). ${ }^{6}$ NEMS incorporates a macroeconomic model that forecasts national energy use and productivity out to 2035 . NEMS produces a set of intermediate outputs, including chained price indices for various sectors of the economy. In the case of refrigerators and freezers, we also examined a forecast based on the Personal Consumption Expenditures - Furniture index that was forecasted for AEO 2011. This index is the most disaggregated category that includes appliances. To develop an inflation-adjusted index, we normalized the above index with the forecasted GDP deflator from AEO 2011. To extend the adjusted index past 2035, we used the average annual growth rate in 2026-2035. This price trend has a long-term real price decline of approximately $2.6 \%$ per year.

Fig. 3 illustrates the full range of price trends for the case of refrigerators and freezers, including the experience curve, the exponential model, and the AEO 2011 forecast. The experience and exponential model were fit to various subsets of the data. The 95\% confidence limits on the experience curve and exponential model are not shown, but

\footnotetext{
${ }^{6} \mathrm{http}: / /$ www.eia.gov/forecasts/aeo/
} 


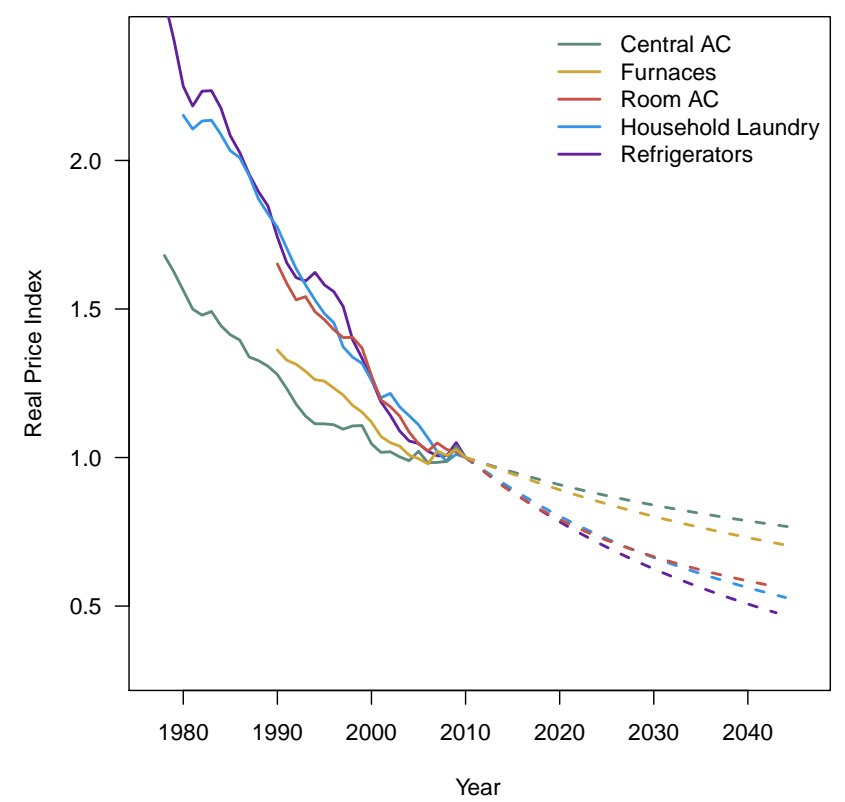

Figure 4: The historical PPI series with the default forecast scenario. All series are normalized such that the price index in 2010 equals 1. Solid lines are historical PPI data. Dashed lines are forecasted trends. Prior analyses assumed a constant price in the forecast. For clothes dryers, the Household Laundry PPI was used.

were also considered as part of the sensitivity analysis. Of all these trends, the trend with the largest price decline was considered as a high sensitivity scenario in our sensitivity analysis, and the smallest price decline was considered as a low sensitivity scenario. The experience curve was the default model in all cases.

The default, high, and low sensitivity scenarios were used in the national impacts analysis (for clothes dryers, we also used the clothes-dryer-only experience rate scenario). These sensitivity scenarios were not considered for the life-cycle cost analysis. Since the life-cycle analysis is based on the first year of compliance only, typically only a few years from publication of a Final Rule, the difference in price deflators amongst the various scenarios will be minimal. Over a 30-year time period, however, the difference can grow to become substantial.

\section{Experience Rates and National Impacts Analysis Results}

Tables 3 and 4 summarize the experience curve and sensitivity results for all the appliances considered in recent energy conservation standards, and Fig. 4 illustrates the historical PPI series and the default projections. The default scenario is used throughout the energy conservation standard analysis (consumer LCC, NIA, manufacturer impact analysis, etc.), whereas the various sensitivities are used to analyze impacts in the NIA 
Table 3: Experience curve fitting results with $95 \%$ confidence limits.

\begin{tabular}{lccc}
\hline Appliance & Experience Rate Parameter $b$ & Experience Rate & $R^{2}$ \\
\hline Central air conditioners and heat pumps & $0.288 \pm 0.021$ & $18.1_{-1.2}^{+1.2} \%$ & 0.960 \\
Clothes dryers & $0.775 \pm 0.034$ & $41.6_{-1.4}^{+1.3} \%$ & 0.987 \\
Furnaces & $0.527 \pm 0.056$ & $30.6_{-2.7}^{+2.6} \%$ & 0.954 \\
Refrigerators and freezers & $0.755 \pm 0.027$ & $40.7_{-1.1}^{+1.1} \%$ & 0.983 \\
Room air conditioners & $0.710 \pm 0.062$ & $38.9_{-2.7}^{+2.6} \%$ & 0.970 \\
\hline
\end{tabular}


Table 4: Results from default, high, low, and special sensitivity scenarios. Clothes dryers included an extra scenario based on market data for clothes dryers only. The other clothes dryer scenarios are based on the household laundry PPI (which includes both clothes washers and dryers). The high and low scenarios for refrigerators and freezers are exponential models instead of experience curves.

\begin{tabular}{lcccc}
\hline Appliance & Default & High & Low & Special \\
\hline Central air conditioners and heat pumps & $E R=18.1 \%$ & $E R=20.5 \%$ & $E R=11.5 \%$ & \\
Clothes dryers & $E R=41.6 \%$ & $E R=42.9 \%$ & $E R=33.9 \%$ & $E R=52.2 \%$ \\
Furnaces & $E R=30.6 \%$ & $E R=33.3 \%$ & $E R=19.2 \%$ & \\
Refrigerators and freezers & $E R=40.7 \%$ & $3.12 \% / \mathrm{yr}$ & $1.14 \% / \mathrm{yr}$ & \\
Room air conditioners & $E R=38.9 \%$ & $E R=41.1 \%$ & $E R=31.0 \%$ & \\
\hline
\end{tabular}

Room air conditioners 


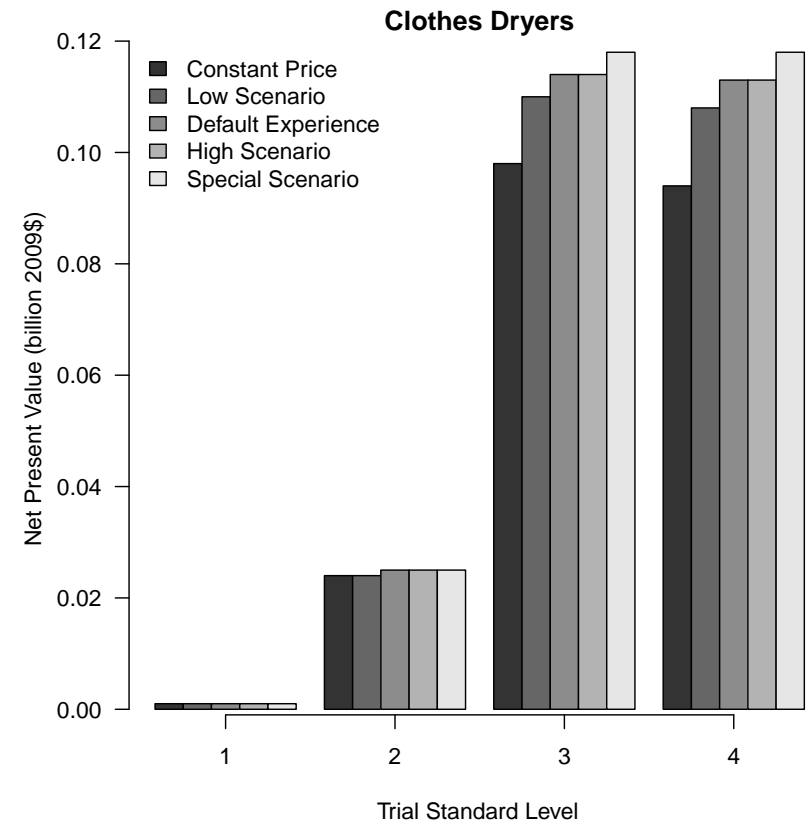

Figure 5: Net present values (NPV) for a variety of trial standard levels (TSL) for residential clothes dryers. The NPV is aggregated across the nation and summed over a 30 -year analysis period, discounted at $7 \%$ per year. Positive NPVs indicate that consumer benefits of potential standards exceed costs. See Section 2.4 for an overview of the appliance standards analysis. Results are from the National Impact Analysis of the recent Direct Final Rule (US Department of Energy, 2011a). Not all TSLs are shown, as some TSLs are significantly negative (not cost-effective). Shown are the NIA results using the previous constant price assumption, a low price trend sensitivity scenario, the default price trend based on an experience curve, and a high price trend sensitivity scenario. Also included is a scenario using clothes-dryer-only price data, as opposed to the household laundry equipment PPI series. The LCC analysis and all downstream analyses use the default price trend only. See Section 2.5 for the definition of the various scenarios. The inclusion of experience has a modest effect on the NPV for clothes dryers. 


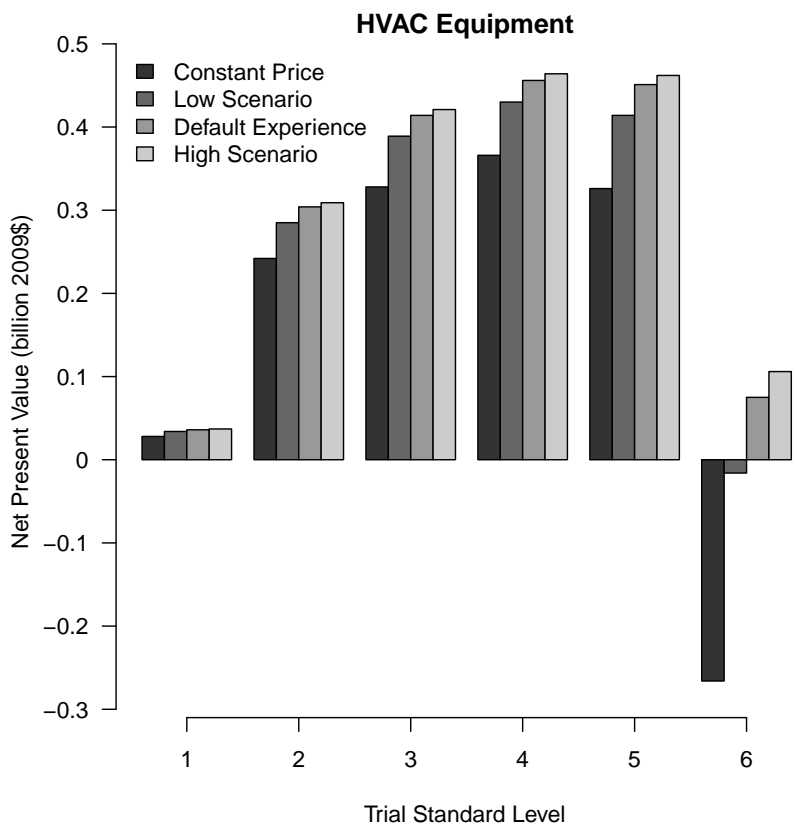

Figure 6: Net present values (NPV) for a variety of trial standard levels (TSL) for residential central air conditioners, central heat pumps, and furnaces, collectively referred to as heating, ventilation, and air-conditioning (HVAC) equipment. The NPV is aggregated across the nation and summed over a 30-year analysis period, discounted at $7 \%$ per year. Positive NPVs indicate that consumer benefits of potential standards exceed costs. See Section 2.4 for an overview of the appliance standards analysis. Results are from the National Impact Analysis of the recent Final Rule (US Department of Energy, 2011b). Not all TSLs are shown, as some TSLs are significantly negative (not cost-effective). Shown are the NIA results using the previous constant price assumption, a low price trend sensitivity scenario, the default price trend based on an experience curve, and a high price trend sensitivity scenario. The LCC analysis and all downstream analyses use the default price trend only. See Section 2.5 for the definition of the various scenarios. The inclusion of experience has a substantial effect on the NPV of the more stringent TSLs. TSL 6 was previously considered to be cost-negative, but the revised analysis demonstrates a benefit. 


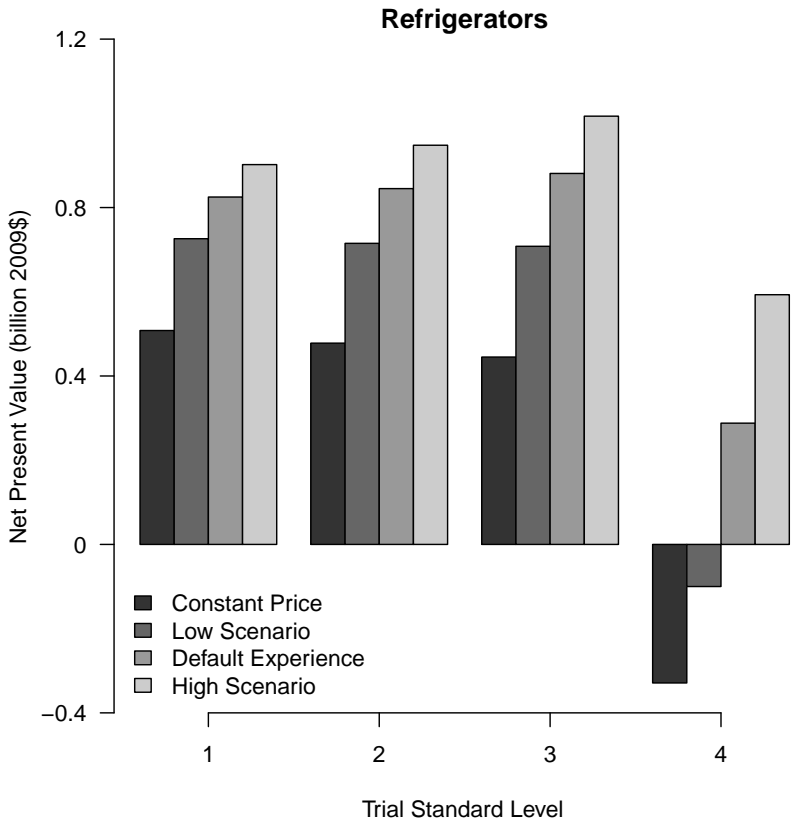

Figure 7: Net present values (NPV) for a variety of trial standard levels (TSL) for residential refrigerators and refrigerator-freezers. The NPV is aggregated across the nation and summed over a 30-year analysis period, discounted at $7 \%$ per year. Positive NPVs indicate that consumer benefits of potential standards exceed costs. See Section 2.4 for an overview of the appliance standards analysis. Results are from the National Impact Analysis of the recent Final Rule (US Department of Energy, 2011c). Not all TSLs are shown for each product class, as some TSLs are significantly negative (not cost-effective). Shown are the NIA results using the previous constant price assumption, a low price trend sensitivity scenario, the default price trend based on an experience curve, and a high price trend sensitivity scenario. The LCC analysis and all downstream analyses use the default price trend only. See Section 2.5 for the definition of the various scenarios. The inclusion of experience has a substantial effect on the NPV of the more stringent TSLs. Some TSLs were previously considered to be cost-negative, but the revised analysis demonstrates a significant benefit. 


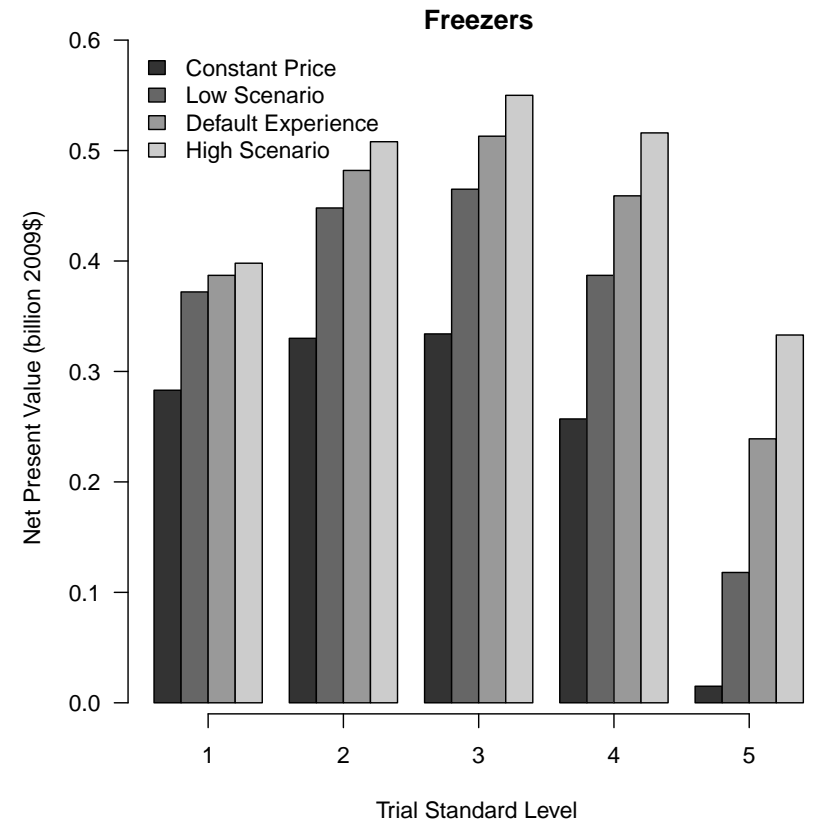

Figure 8: Net present values (NPV) for a variety of trial standard levels (TSL) for residential freezers. The NPV is aggregated across the nation and summed over a 30-year analysis period, discounted at $7 \%$ per year. Positive NPVs indicate that consumer benefits of potential standards exceed costs. See Section 2.4 for an overview of the appliance standards analysis. Results are from the National Impact Analysis of the recent Final Rule (US Department of Energy, 2011c). Not all TSLs are shown for each product class, as some TSLs are significantly negative (not cost-effective). Shown are the NIA results using the previous constant price assumption, a low price trend sensitivity scenario, the default price trend based on an experience curve, and a high price trend sensitivity scenario. The LCC analysis and all downstream analyses use the default price trend only. See Section 2.5 for the definition of the various scenarios. The inclusion of experience has a substantial effect on the NPV of the more stringent TSLs. Some TSLs were previously considered to be cost-negative or cost-neutral, but the revised analysis demonstrates a significant benefit. 


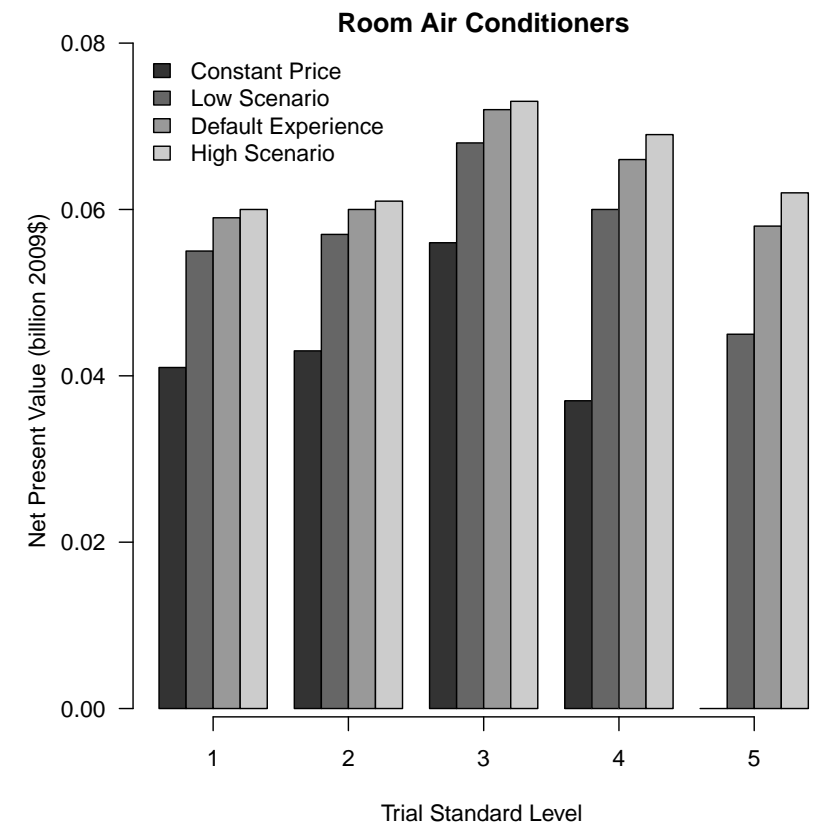

Figure 9: Net present values (NPV) for a variety of trial standard levels (TSL) for residential room air conditioners. The NPV is aggregated across the nation and summed over a 30 -year analysis period, discounted at $7 \%$ per year. Positive NPVs indicate that consumer benefits of potential standards exceed costs. See Section 2.4 for an overview of the appliance standards analysis. Results are from the National Impact Analysis of the recent Direct Final Rule (US Department of Energy, 2011a). Not all TSLs are shown, as some TSLs are significantly negative (not cost-effective). Shown are the NIA results using the previous constant price assumption, a low price trend sensitivity scenario, the default price trend based on an experience curve, and a high price trend sensitivity scenario. The LCC analysis and all downstream analyses use the default price trend only. See Section 2.5 for the definition of the various scenarios. The inclusion of experience has a substantial effect on the NPV of the more stringent TSLs. TSL 5 was previously considered to be cost-neutral, but the revised analysis demonstrates a significant benefit. 
only. As these experience rates are derived using domestic shipments only, they represent apparent experience rates in the U.S. (see Section 4.2 for further discussion). The majority of these appliances have experience rates above $30 \%$, with only central air conditioners below $20 \%$ (in the default scenario).

The inclusion of experience curves can significantly affect the NPV of the aggregated national economic impacts for a potential standard. Figs. 5-9 demonstrate the results of including experience curves in the NIA, with the NPV discounted at $7 \%$ per year. For most appliances, the NPV rises significantly compared to the constant price assumption, indicating a larger national benefit from potential standards. The effect is more dramatic for higher TSLs (i.e., more stringent potential standards), where the cost premium is larger. This is realistic - in reality newer (and therefore more expensive) technologies will undergo more rapid experience than more mature technologies, therefore one intuitively expects the higher TSLs to show a more pronounced experience effect. In a few cases (such as refrigerators and HVAC equipment) the NPV actually changes sign for some TSLs. A previously uneconomical potential standard level becomes economical when incorporating experience curves.

It is important to note that the NIA includes many other factors than simply purchase price and operating cost. The model includes installation costs, repair costs, purchase price elasticities, early replacement effects, fuel switching (for certain products), and other effects. None of these are affected by experience as derived above. Nevertheless, the purchase price is usually the dominant factor, and thus including experience curves in the analysis is important (though installation can be significant for some appliances).

Given that experience curves are more representative of actual market behavior than a constant price assumption, our results imply that previous appliance standards analyses, guided by the older methodology, may have undervalued the potential benefits of proposed standard levels. This may have led to settling on a lower standard level as a result. For example, suppose the policy choice is based on the maximum TSL with a positive NPV, then incorporating experience curves can result in choosing a higher TSL for HVAC equipment and refrigerators. If the policy choice is based on the TSL with the maximum NPV, however, the effect on the policy choice is much more limited, and potentially only affects refrigerators. It is also important to note that the policy choice is based on many other factors in addition to the national NPV (e.g., manufacturer impacts). Nevertheless, the final consumer NPV estimates are much larger than when assuming constant prices, and thus the cumulative economic benefits of the appliance standards program have likely been significantly underestimated in the past.

\section{Discussion}

\subsection{General Methodology Comments}

The ideal implementation of experience curve analysis would include detailed cost data for each efficiency level, for each individual product. Such data are virtually impossible to obtain for the U.S., however, and so we must rely on lower resolution data such as the PPI. Furthermore, past trends are no guarantee of future performance. Nevertheless, the PPI data show persistent, significant, and lengthy historical trends, 
and are therefore a more rational indicator of future trends than an assumption of no changes. The sensitivity analysis looks at the effects of historical fluctuations, recent trends, fitting variations, and data variations (e.g., looking at lower quality but more product-specific data). The 30-year forecast may be sensitive to errors in the experience curve analysis, but such forecast errors are diminished by the discounting adopted in the NIA. Ultimately, in the cases discussed here, the policy choice based on the NPV results is the same regardless of whether the low, default, or high scenario is considered.

The experience model utilized in our analysis is straightforward and is a proxy for a variety of underlying casual factors. We recognize the limitations of such a simple model, and acknowledge that future work is needed in assessing the reliability and applicability of experience curves in policy analysis (Jamasb \& Köhler, 2008; Ferioli et al., 2009). Adopting a more complex experience model, however, is not justified by the relatively limited and low resolution data, as any model with additional parameters may overfit the data. We additionally do not have data for high-efficiency and baseline products separately. It is also plausible that appliance experience is in reality driven by component-level innovations, and that a component-level model is perhaps a better indication of true experience (Ferioli et al., 2009). Our adopted experience curve model is therefore simple and conservative, but is ultimately more representative of real-world dynamics than the previously used constant price assumption.

\subsection{Apparent Experience}

Since the focus of this work is domestic, we rely only on domestic shipments (i.e., cumulative production intended for domestic consumption). The analyses conducted for DOE energy conservation standards are similarly restricted to domestic consumption. Appliance manufacturing is concentrated in a few multinational corporations, however, and major changes in one market can impact other markets substantially. True experience is a dynamic of global production and distribution, with different regional factors having more or less influence on product price. A manufacturer will learn from all production lines and apply improvements globally. This is especially true for new technologies incorporated into appliance designs. New premium and efficient features are introduced predominantly in one market at first, and then diffuse into the remaining global markets.

Costs as perceived in the U.S. are likely changing faster than would be driven by domestic shipments alone, because domestic shipments are only a fraction of total shipments. The fraction of U.S. shipments relative to global production is also changing, and has diminished with time. We therefore distinguish an experience rate calculated using only domestic shipments as an apparent experience rate. Nevertheless, utilizing the apparent experience rate makes sense from a domestic energy policy context. Mandatory efficiency standards, for example, focus only on domestic energy-saving impacts. When calculating the national net present value of a possible minimum efficiency standard, the apparent experience rate is the correct value to use. Domestic consumers benefit fully from global production experience, despite purchasing only a fraction of total global production. It is for this reason that our experience values differ from those in Weiss et al. (2010b), and from other historical studies of experience in appliance manufacturing. 
We note that this distinction confounds the experience curve literature in general, not just its application to energy efficiency standards. For example, the impressive review of Weiss et al. (2010a) documents the results of 75 different experience curve analyses. There is no consistency in the independent and dependent variables for each, however, with some studies pairing domestic prices with global production, others pairing domestic prices with domestic production, and others not specifying. There is good reason for this confusion, with mixed markets and major shifts in the relative influences of those markets through the decades. Domestic appliance energy policy, however, is based on domestic shipments and domestic economic benefits, and thus in this instance, the data needs are clear.

\subsection{Characteristics of PPI as a Cost Indicator}

The producer prices on which the PPI is based are only a close approximation of manufacturing costs. True manufacturing costs, both fixed and variable, are generally not available in a time series (indeed they are often proprietary). Therefore, even though experience curves are strictly a (mostly variable) manufacturing and distribution cost effect, we must rely on the producer prices for our analysis. Nevertheless, PPI is based on a wholesale price, not a retail price, so it is not subject to factors that affect retail prices. The use of PPI indicates long-term declining real price trends for many products.

The PPI also includes a quality adjustment, which attempts to factor out physical changes (such as capacity, premium features, government-mandated features, etc.) in the product that affect the price. ${ }^{7}$ The BLS uses a variety of methods to determine this quality adjustment, including comparing similar models from year to year, asking manufacturers to explicitly separate out value-added cost increases, and potentially using a hedonic model. For this reason, the PPI is a better measure of experience curve effects than actual wholesale prices would be, since changes in PPI should reflect production cost changes due to industrial productivity improvements and other advances in technology rather than changes driven by enhanced features.

The BLS does not explicitly correct for changing product efficiency in the CPI, but the PPI likely accounts for improvements in the energy efficiency of the device because such changes are generally physical changes. This quality adjustment is exactly what the appliance standards analysis, based on an engineering cost-efficiency curve, requires. Although experience curve analysis has been applied to residential appliances for decades, and many analyses account for variability or changes in the service delivered per unit, in general the change in the energy efficiency of appliances is not accounted for, except in cases in which energy delivery or conservation is the end service delivered. Weiss et al. (2010a,b) document numerous cases of capacityrelated normalizations. For example, clothes washers and dryers, dishwashers, and refrigerators are frequently, though not always, normalized with respect for volume, and computer memory is consistently normalized for megabytes of DRAM. In cases where energy efficiency and delivery are not the end-use service delivered, however, efficiency is generally not accounted for. Yet appliances have significantly reduced their

${ }^{7}$ BLS Handbook of Methods, Chapter 14. http://www.bls.gov/opub/hom/homch14.htm 
energy consumption over the time period considered in these experience curve analyses (e.g., refrigerators currently use approximately $70 \%$ less energy than in the 1970s). In contrast, energy service technologies like photovoltaics, lighting, heating, building insulation, advanced glazing, and electricity generators are usually (though not always) normalized for the energy delivered or conserved. Usage of the PPI to analyze experience curve effects is therefore advantageous since energy efficiency is likely included as part of the quality adjustment. This yields a fairer, more realistic experience rate estimate that is not biased toward lower values due to constantly improving efficiency.

The PPI is based only on domestic manufacturing. Although a majority of appliance manufacturing is now performed overseas, there are still some appliance models manufactured domestically, and historically the share of appliances produced domestically was much larger. Thus the PPI is still a meaningful indicator. Labor costs can be an important component of variable manufacturing costs, however, and since outsourcing is not reflected in the PPI time series, using it results in a conservative estimate of the experience rate. We do not attempt to forecast the impact of future outsourcing of production (or increase in imports generally) in our forecasts of appliance manufacturing costs.

Finally, we note that producer prices will include the effects of taxes, import tariffs, and other non-tariff import barriers. This is true even if products are manufactured domestically, as component parts may be imported. Such barriers may significantly affect the production cost and consumer price (without physically changing the product), and are likely to substantially change over the long time periods considered here. The experience curves presented here therefore implicitly include such effects, in addition to changes in manufacturing efficiency.

\subsection{Comparison of PPI to Market Data and Previous Studies}

In order to address some of the potential issues relevant to using the PPI, we performed a cross-check of PPI data with actual market data. We used market price data gathered as part of the refrigerator and freezer rulemaking activity, obtained from the market research firm NPD. ${ }^{8}$ The data include monthly units sold and total price at the point of sale (retail) over a period of 24 months, and we compared this to the monthly refrigerator-only and freezer-only PPI series ${ }^{9}$ over the same time period. NPD includes many large retailers and covers a significant fraction of the market; we therefore assume it is representative of the whole market. The NPD data are actual point-of-sale prices paid by consumers, and therefore include all possible sales, promotions, and discounts. Using only 2 years worth of data limits the extent of any physical changes that might have occurred in refrigerators and freezers, enabling a cleaner comparison of PPI and market data, and yet provides 23 monthly data points (January 2007 to November 2008 inclusive).

We derived the following monthly series from the NPD data, for both refrigerators and freezers: (a) the sales-weighted average price of all units sold; and (b) the average

\footnotetext{
${ }^{8}$ http://www.npd.com

${ }^{9}$ Series ID PCU3352223352221 \& PCU3352223352222
} 
Table 5: Correlation coefficients between PPI and market price data.

\begin{tabular}{llcc}
\hline Appliance & Series Pair & $\begin{array}{c}\text { Pearson Correlation } \\
\text { Coefficient }\end{array}$ & P-Value \\
\hline Refrigerators & Monthly PPI-NPD (a) & 0.66 & $6.3 \times 10^{-4}$ \\
& Monthly PPI-NPD (b) & 0.77 & $1.8 \times 10^{-5}$ \\
\hline Freezers & Monthly PPI-NPD (a) & 0.68 & $3.4 \times 10^{-4}$ \\
& Monthly PPI-NPD (b) & 0.79 & $6.6 \times 10^{-6}$ \\
\hline Refrigerators \& Freezers & Yearly PPI-Dale et al. (2009) $^{-}$ & 0.92 & $1.3 \times 10^{-4}$ \\
\hline Clothes Washers & Yearly PPI $^{a}$-Dale et al. (2009) & 0.86 & $7.6 \times 10^{-5}$ \\
\hline
\end{tabular}

${ }^{a}$ The PPI series applicable for clothes washers is the household laundry equipment series, which also includes clothes dryers. 
Table 6: Comparison of long-term real price trends derived in this study with values from the literature. This study relies on PPI data, whereas previous studies obtained market price data from market research firms. All price data have been deflated to real dollars using a consumer index appropriate for the region analyzed.

\begin{tabular}{|c|c|c|c|c|}
\hline Study & Region & Time Period & Appliance & $\begin{array}{c}\text { Approximate Real Price Decline } \\
(\% / \text { year })\end{array}$ \\
\hline \multicolumn{5}{|c|}{ Household Laundry Equipment } \\
\hline This study & USA & $1980-2010$ & Clothes Washers \& Dryers & $1.9 \%$ \\
\hline Bass (1980) & USA & $1950-1974$ & Electric Clothes Dryers & $2.2 \%$ \\
\hline Laitner \& Sanstad (2004) & USA & $1980-1998$ & $\begin{array}{c}\text { Clothes Washers } \\
\text { Electric Clothes Dryers } \\
\text { Gas Clothes Dryers }\end{array}$ & $\begin{array}{l}3.4 \% \\
3.2 \% \\
2.9 \%\end{array}$ \\
\hline Dale et al. (2009) & USA & 1983-2001 & Clothes Washers & $2.4 \%$ \\
\hline EES (2006) & Australia & 1993-2005 & $\begin{array}{l}\text { Clothes Washers } \\
\text { Clothes Dryers }\end{array}$ & $\begin{array}{l}2.6 \% \\
1.1 \%\end{array}$ \\
\hline Weiss et al. (2010b) & Netherlands & $\begin{array}{l}1965-2008 \\
1969-2003\end{array}$ & $\begin{array}{l}\text { Clothes Washers } \\
\text { Clothes Dryers }\end{array}$ & $\begin{array}{l}2.4 \% \\
2.1 \%\end{array}$ \\
\hline \multicolumn{5}{|l|}{ HVAC Equipment } \\
\hline This study & USA & $\begin{array}{l}1990-2009 \\
1978-2010\end{array}$ & $\begin{array}{c}\text { Room AC } \\
\text { Central AC }\end{array}$ & $\begin{array}{l}1.7 \% \\
0.8 \%\end{array}$ \\
\hline Bass (1980) & USA & 1946-1974 & Room AC & $2.5 \%$ \\
\hline Laitner \& Sanstad (2004) & USA & 1980-1998 & Room AC & $4.0 \%$ \\
\hline Dale et al. (2009) & USA & $\begin{array}{l}1975-1994 \\
1965-1986\end{array}$ & $\begin{array}{l}\text { Room AC } \\
\text { Central AC }\end{array}$ & $\begin{array}{l}1.5 \% \\
1.0 \%{ }^{a}\end{array}$ \\
\hline \multicolumn{5}{|l|}{ Refrigerators and Freezers } \\
\hline This study & USA & $1951-2007$ & Refrigerators \& Freezers & $2.5 \%$ \\
\hline Bass (1980) & USA & $1922-1940$ & Refrigerators & $2.6 \%$ \\
\hline Laitner \& Sanstad (2004) & USA & 1980-1998 & $\begin{array}{l}\text { Refrigerators } \\
\text { Freezers }\end{array}$ & $\begin{array}{l}3.2 \% \\
5.3 \% \\
\end{array}$ \\
\hline Dale et al. (2009) & USA & 1980-2001 & Refrigerators & $2.5 \%$ \\
\hline Schiellerup (2002) & UK & 1992-1999 & $\begin{array}{l}\text { Refrigerators } \\
\text { Freezers }\end{array}$ & $\begin{array}{c}6.3 \% \\
5.0-5.1 \%\end{array}$ \\
\hline EES (2006) & Australia & 1993-2005 & $\begin{array}{c}\text { Refrigerators } \\
\text { Freezers }\end{array}$ & $\begin{array}{l}1.7 \% \\
2.5 \% \\
\end{array}$ \\
\hline Weiss et al. (2010b) & Netherlands & $\begin{array}{l}1964-2008 \\
1970-2003\end{array}$ & $\begin{array}{l}\text { Refrigerators } \\
\text { Freezers }\end{array}$ & $\begin{array}{c}1.2 \% \\
1.1-1.5 \%\end{array}$ \\
\hline
\end{tabular}

${ }^{a}$ The central AC time series in Dale et al. (2009) is very noisy. The real price decline presented here uses the average of the first two years of data and the average of the last two years of data as endpoints. 


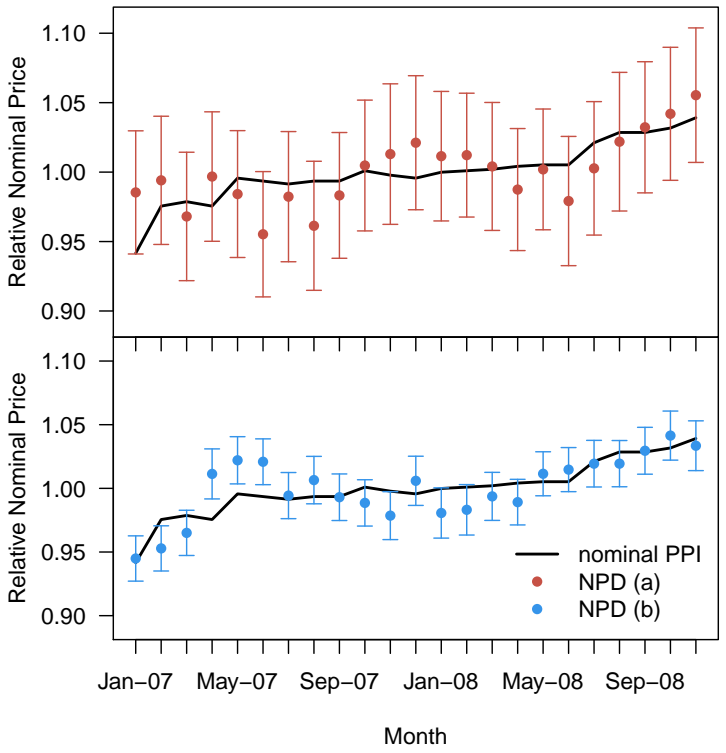

Figure 10: Comparison of the historical monthly refrigerator-only PPI series with refrigerator market data from NPD. Shown are both the sales-weighted average price (a) and the average model price (b) of all units sold in a given month. The PPI series and both NPD series are normalized such that the 2-year average equals 1. Error bars represent 1 standard deviation from the mean (the width of the distribution is much larger). 

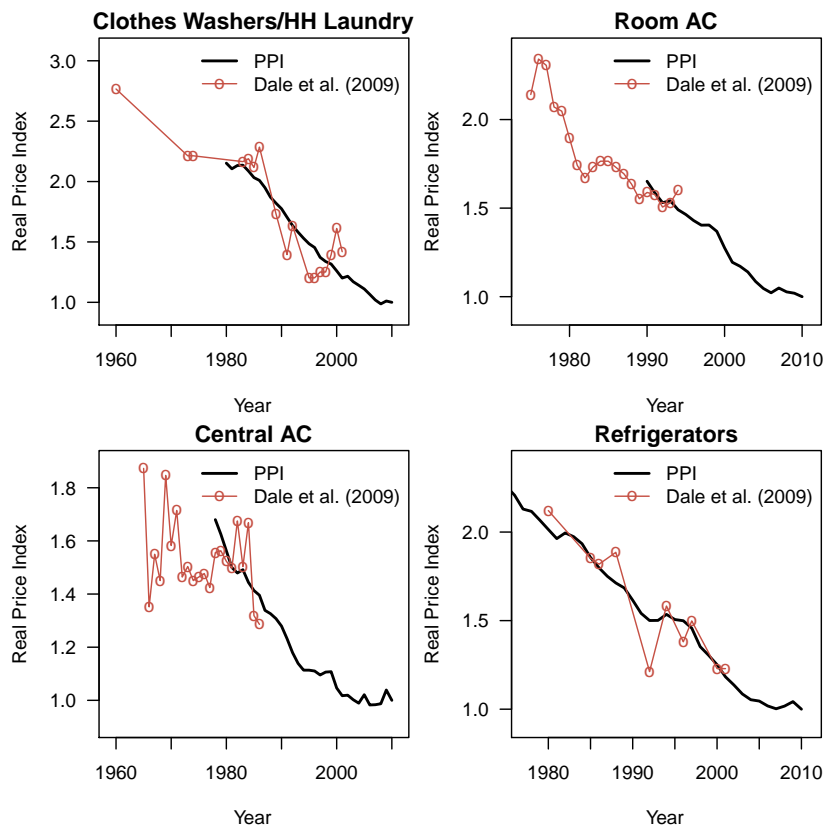

Figure 11: Comparison of historical PPI trends with retail market price data from Dale et al. (2009) for refrigerators, room air conditioners, clothes washers, and central air conditioners. These data were obtained from various catalogues and Consumer Reports. The clothes washer data are compared to the household laundry equipment PPI series. The PPI series are normalized to 1 in 2010 . The market price data are normalized such that average over the period of overlap with the PPI series is equal to the average PPI over the same period. 
model price of all models sold. The NPD market data are inherently variable, as consumer spending habits fluctuate and retailers offer discounts. NPD also does not cover $100 \%$ of the market. Nevertheless, there is good agreement in the general price trend between the PPI and the series derived from NPD data, as illustrated in Fig. 10 for refrigerators. Since the time period is only 2 years, the models available for purchase are likely to remain relatively constant, which is why we include the derived series (b). Table 5 lists the Pearson correlation coefficients of the PPI series with the NPD series. All are significantly correlated and the null hypothesis is rejected with over $99 \%$ confidence, even given the relatively shallow trend over the 2 -year time period (correlation tests are not possible with a constant function). This provides reassurance and verification that the PPI series are representative of changes in product prices. The correlations will not be perfect because the PPI is quality-adjusted but the NPD data are not. The adjustment over a 2-year period will be small but not necessarily zero.

In addition, we also compared the PPI series used in determining the experience rates with trends and market price data in the literature. Fig. 11 compares data from Dale et al. (2009), originally obtained from catalogues and Consumer Reports. Dale

et al. restricted the price data to specific capacities and types of appliances (e.g., an 18 $\mathrm{ft}^{3}$ top-mount refrigerator), so these data are partially quality-adjusted. For all appliances except perhaps central air conditioners, the trends in the PPI series qualitatively correlate very well with market price data. The market price data gathered by Dale et al. for central air conditioners may not be representative of actual prices. Central air conditioners are generally contractor purchased and installed appliances, and are rarely purchased by consumers directly through retail, leading to a potential discrepancy between catalogue prices and prices actually paid by the contractor. This may explain some of the discrepancy between Dale et al. (2009) and the PPI series. Table 5 lists the Pearson correlation coefficients for refrigerators \& freezers and clothes washers, the only two appliance categories with sufficient overlapping years to calculate a correlation coefficient. In addition, it has been shown that in the last few decades, the PPI data track reasonably well with quality-corrected prices obtained from consumer catalogues (Gordon, 1990). The price trends derived in this study for all appliances are consistent with other previous domestic and international studies (see Table 6).

\subsection{Cost Reductions at Constant Efficiency}

As described in Section 4.3, it is important to consider price changes at constant efficiency, especially given the remarkable progress in appliance efficiency in the last 30 years due to strong energy policy drivers. Prices and energy use have both fallen significantly over a long period of time. ${ }^{10}$ In a few cases, data exist that can be used to illustrate the reductions in appliance production cost at constant efficiencies. The appliances covered here have all had recent updates of their energy conservation standards. The TSDs published by DOE in support of these rulemakings include an engineering analysis, which establishes the cost-efficiency curve for a given appliance (i.e.,

\footnotetext{
${ }^{10}$ Note that there is no strong competition for appliance energy use as there is for purchase price. As a result, cumulative production is unlikely to be an explanatory variable for changing energy use as it is for purchase price.
} 
the incremental manufacturing costs for a given incremental efficiency improvement). The TSDs are available for both the recent rulemakings as well as past rulemakings, complete with an older engineering analysis and cost-efficiency relationship. (The last standard for clothes dryers was issued in 1991, and its engineering analysis is unavailable.)

The manufacturing costs used in these analyses are obtained via confidentially submitted manufacturing data and/or from manufacturer interviews, as well as by detailed tear-down analysis. By comparing the older and newer cost-efficiency relationships, it is possible to determine how manufacturing costs have changed for a given efficiency, in the time separating the two rulemakings. The update frequency is typically once every 6-10 years (potentially longer) during which time technologies can change substantially. Given this large time span, there is often only limited overlap between older and newer cost-efficiency relationships. In some cases there is no overlap at all. Nevertheless, these cost-efficiency curves provide an important qualitative insight. A design option that was once considered very efficient and carried a significant cost premium can become today's baseline option.

Figs. 12-15 show the cost-efficiency curves for room air conditioners, central air conditioners (including split ACs, packaged ACs, split heat pumps, and packaged HPs), furnaces, refrigerators, and freezers. Calculating experience rates by efficiency levels is not possible, since shipment data by efficiency level are not available, although we can make qualitative comparisons.

In all cases, the manufacturing cost for a given efficiency level has declined significantly, by as much as $60 \%$ over 14 years for room air conditioners, $30 \%$ over 11 years for central air conditioners, 55\% over 4 years for furnaces, and $40 \%$ over 15 years for refrigerators. This is compared to a decline in PPI of approximately $25 \%, 5 \%$, and $33 \%$ for room air conditioners, central air conditioner, and refrigerators respectively, over the same time periods (using the default experience rate). The PPI for furnaces is essentially flat in the last 4 years. This highlights the difference between high-efficiency units vs. average units, in that costs associated with high-efficiency units (often with small or zero market share at the time of the analysis) will likely decline much faster than an average unit. This is especially true in the case of furnaces, for which only 4 years separate the two engineering analyses, and yet we see a 55\% drop in manufacturing costs for the most efficient units. In the case of packaged heat pumps, there was no overlapping efficiency level in the two engineering analyses. It is worth noting, however, that the maximum level analyzed and deemed viable in 1999 was 12 SEER (seasonal energy efficiency ratio), whereas the baseline packaged heat pump was 13 SEER in 2010.

This comparison of bottom-up engineering analysis from successive appliance standards rulemakings underscores the need to include experience in the standards analysis. The cost deflators used in our experience curve analysis likely underestimate the actual decline in manufacturing costs, especially for the high-efficiency TSLs. Including even a conservative estimate of experience, however, is an improvement over the previous constant price assumption that is inconsistent with historical data. 


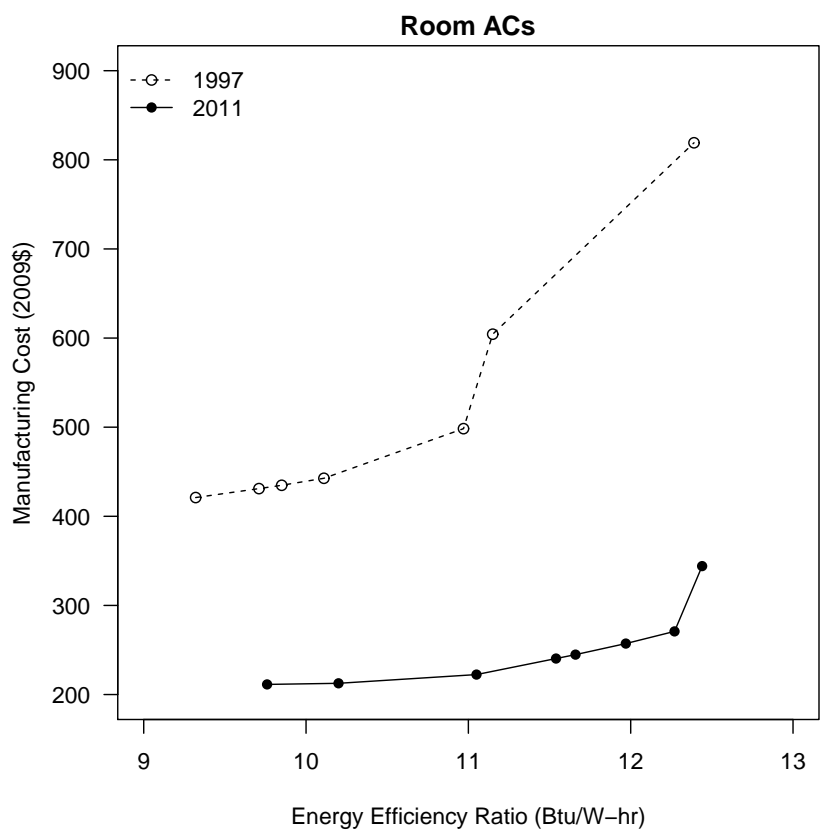

Figure 12: Comparison of past and recent cost-efficiency curves for room air conditioners. Results are from the engineering analyses in support of appliance efficiency standards (US Department of Energy, 1997, Volume 2, Table 1.12; US Department of Energy, 2011a, Appendix 5D, Table 5-D.2.3). These cost-efficiency curves represent averaged or interpolated costs for a typical 12,000 Btu/hr louvered room air conditioner. Prices have been deflated using the CPI. 

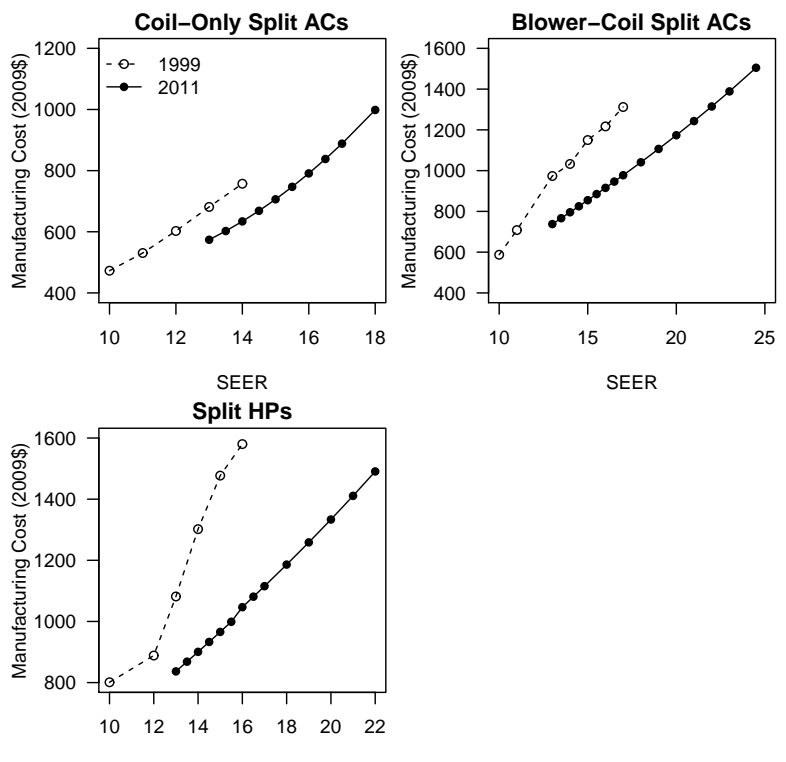

SEER

Figure 13: Comparison of past and recent cost-efficiency curves for central air conditioners and heat pumps. Results are from the engineering analyses in support of appliance efficiency standards (US Department of Energy, 1999, Chapter 4, Table 4.7; US Department of Energy, 2011b, Chapter 5, Tables 5.13.4, 5.13.7, \& 5.13.10). These cost-efficiency curves represent averaged or interpolated costs for a typical two-ton central air conditioner or heat pump. Prices have been deflated using the CPI 


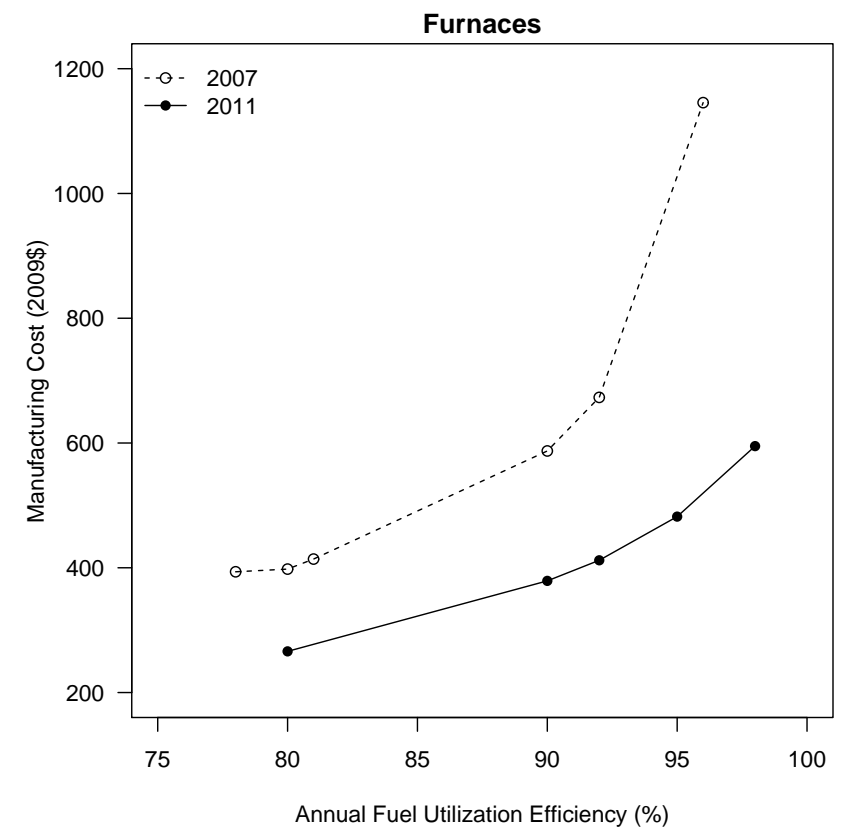

Figure 14: Comparison of past and recent cost-efficiency curves for residential furnaces. Results are from the engineering analyses in support of appliance efficiency standards (US Department of Energy, 2007, Appendix E, Table E.1.1; US Department of Energy, 2011b, Chapter 5, Table 5.13.1). These cost-efficiency curves represent averaged or interpolated costs for a typical 75,000-80,000 Btu/hr non-weatherized furnace. Prices have been deflated using the CPI. 

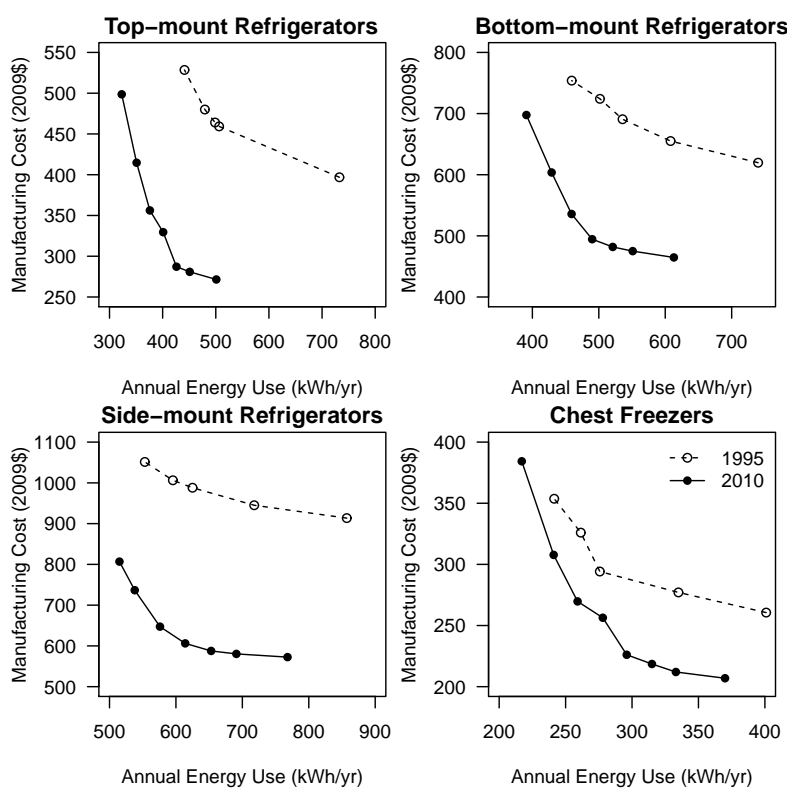

Figure 15: Comparison of past and recent cost-efficiency curves for residential refrigerators and freezers Results are from the engineering analyses in support of appliance efficiency standards (US Department of Energy, 1995, Chapter 3, Tables 3.6, 3.8, 3.9, \& 3.12; US Department of Energy, 2011c, Chapter 5, Tables 5.9.1 \& 5.9.2). These cost-efficiency curves represent averaged or interpolated costs for a typical $18 \mathrm{ft}^{3}$ topmount auto-defrost refrigerator, $22 \mathrm{ft}^{3}$ side-mount auto-defrost refrigerator with through-the-door ice service, $20 \mathrm{ft}^{3}$ bottom-mount auto-defrost refrigerator, and $15 \mathrm{ft}^{3}$ manual-defrost chest freezer. Annual energy use values from the older engineering analysis have been adjusted to the revised test procedure (with new compartment temperatures), as described in US Department of Energy (2011c). Prices have been deflated using the CPI. 


\subsection{Considerations for Future Analyses}

The methodology outlined here treats baseline models and highly efficient models in the same way. The PPI does not distinguish between the two, and the calculated experience rates are applied to both equally. In reality, because the baseline models and the highly efficient models are at different maturity stages, their experience rates are likely not the same. High-efficiency models tend to incorporate newer technology, and we would expect such models to experience faster cost declines than more mature technology since the time period required to double the cumulative production of newer technology is shorter than for technology long on the market. The use of the PPI to determine the experience curve for the product as a whole will tend to undervalue the potential economic benefits for higher efficiency models. Ideally, we would utilize appliance price histories broken down by efficiency class, and if at all feasible, by important components (e.g., compressors, heat exchangers, vacuum panels, etc.).

Unfortunately, at this time we are not aware of robust data sufficient to separately analyze baseline models and efficient models. Such data are virtually non-existent in the U.S., though these data are collected in Europe and Australia in support of their efficiency standards. Future analyses would benefit from an institution or agency implementing a program to make such data available in the U.S. These data could then be used to develop more sophisticated experience curves for baseline and efficient models.

A few appliances and some commercial equipment are heavily affected by volatile commodity prices. For some, such as transformers and motors, a significant fraction of the manufacturing cost is in obtaining the raw materials such as copper, aluminum, and steel. This is confirmed by the PPI series for these products, which are not monotonic and correlate strongly with the historical prices of commodity metals. The prices of these commodities depend on many factors and cannot be easily forecasted. For future analyses, historical commodity data could be used to determine whether commodity price volatility is a concern for estimating an experience rate for specific products. In such cases, and with sufficient cost and/or price data, it might be possible to factor out commodity price volatility and determine an experience rate for the non-commodity component of the manufacturing cost/producer price.

In cases with limited or no data, it is worth considering using data at a higher level of aggregation to determine a range of experience rates. This approach has already been adopted to some degree with household laundry equipment. For some product categories, there may not be suitable PPI data to properly characterize the experience curve. In such instances, using the AEO price trend as a default scenario is perhaps the best approach, and is more representative of actual markets than assuming a priori that costs remain constant in the 30-year analysis period.

The improvements outlined above will enhance the statistical certainty of the experience curve estimate and the completeness of any future model. Additional data should enable an improved evaluation of the potential impacts and of all the factors that can influence equipment cost and price trends over time. Such data will also enable a more sophisticated sensitivity analysis. 


\section{Summary}

Historically, technical analyses performed in support of national energy efficiency appliance standards have forecasted equipment prices to be constant over the analysis period. This assumption-based approach of a constant real price trend is not consistent with the historical data for many products, including consumer durable goods. Inflation-adjusted producer price data for appliances exhibit persistent price declines over several decades. The constant cost assumption used in previous energy efficiency standards analyses may therefore underestimate the consumer benefits of more stringent standards.

Experience curve analysis can be used to obtain more representative price forecasts for appliances, as was done for the analyses in support of recent appliance energy efficiency standards (for clothes dryers, room air conditioners, central air conditioners and heat pumps, furnaces, refrigerators, and freezers). This is an approach with a strong theoretical and empirical foundation, utilized across many disciplines, and is advocated for use in energy technology policy by the Organization for Economic Cooperation and Development and the International Energy Agency (IEA, 2000). When incorporating experience curves, the recent appliance standards analyses yielded significantly larger net present values than when using the constant price assumption. For some trial standard levels, the net present value changed sign, suggesting that previous rulemakings may have undervalued the consumer benefits of appliance efficiency standards.

In recognition of the uncertainty in experience curve analysis, we adopted several sensitivity scenarios. The scenarios were used in the national impact analysis to examine the dependence of the results on different assumptions about experience. While there are some differences between high and low sensitivity scenarios, the policy choice generally remains unchanged. There is, however, a drastic difference compared to the constant price assumption.

Although incorporating experience curves in appliance standards analysis represents a significant step forward, further research is needed to properly account for several other factors, including commodity price volatility and differences between baseline and high-efficiency products. Cost reductions are often more pronounced in newer-technology products. The current implementation described here is therefore conservative, but is ultimately a more representative projection of future prices than the constant price assumption.

\section{Acknowledgments}

We wish to thank Katie Coughlin, Larry Dale, Jeffery Greenblatt, and two anonymous reviewers for helpful comments. We also thank Arpi Kupelian, who assisted us on a previous iteration of this work. The Energy Efficiency Standards group at Lawrence Berkeley National Laboratory is supported by the U.S. Department of Energy's Office of Energy Efficiency and Renewable Energy, Building Technologies Program under Contract No. DE-AC02-05CH11231. 


\section{References}

Alchian, A., 1963. Reliability of progress curves in airframe production. Econometrica 31 (4), 679-693.

Argote, L., Epple, D., 1990. Learning curves in manufacturing. Science 247 (4945), 920-924.

Arrow, K., 1962. The economic implications of learning-by-doing. Review of Economic Studies 29 (3), 155-173.

Bailey, A.G., Bui, Q.M., Farmer, J.D., Margolis, R., Ramamoorthy, R., 2012. Forecasting Technological Progress. Proceedings of the International Workshop on Complex Sciences in the Engineering of Computing Systems.

Bass, F. M., 1980. The relationship between diffusion rates, experience curves, and demand elasticities for consumer durable technological innovations. Journal of Business 53 (3), S51-67.

Baumol, W.J., 1967. Macroeconomics of unbalanced growth: The anatomy of urban crisis. The American Economic Review 57 (3), 415-426.

Baumol, W.J., Blackman, S.A.B., Wolff, E.N., 1985. Unbalanced growth revisited: Asymptotic stagnancy and new evidence. The American Economic Review 75 (4), 806-817.

BCG, 1972. Perspectives on Experience. Boston Consulting Group, Boston.

BCG, 1980. The Experience Curve Revisited. Boston Consulting Group, Boston.

Dale, L., Antinori, C., McNeil, M., McMahon, J.E., Fujita, K.S., 2009. Retrospective evaluation of appliance price trends. Energy Policy 37, 597-605.

Day, G. S., Montgomery, D. B., 1983. Diagnosing the experience curve. Journal of Marketing 47 (2), 22-58.

Dutton, J. M., Thomas, A., 1984. Treating progress functions as a managerial opportunity. Academy of Management Review 9 (2), 235-247.

EES, 2006. Greening white goods: a report into the energy efficiency trends of major household appliances in Australia from1993-2005. Prepared by Energy Efficiency Strategies for Equipment Energy Efficiency (E3) Committee.

Ellis, M., Jollands, N., Harrington, L., Meier, A., 2007. Do energy efficient appliances cost more? Proceedings of 2007 ECEEE Summer Study.

Ferioli, F., Schoots, K., van der Zwaan, B.C.C., 2009. Use and limitations of learning curves for energy technology policy: A component-learning hypothesis. Energy Policy 37, 2525-2535.

Fusfeld, A. R., 1973. The technological progress function. Technology Review (February), 29-38. 
Gordon, R.J., 1990. Electrical appliances, in: The measurement of durable goods prices. University of Chicago Press, Chicago, pp. 241-320.

Greaker, M., Sagen, E.L., 2008. Explaining experience curves for new energy technologies: A case study of liquefied natural gas. Energy Economics 30, 2899-2911.

Gruber, H., 1992. The learning curve in the production of semiconductor memory chips. Applied Economics 24 (8), 885-894.

Hirsh, W.Z., 1952. Manufacturing progress functions. Review of Economics and Statistics 34 (2), 143-155.

IEA, 2000. Experience Curves for Energy Technology Policy. International Energy Agency, Paris.

Ibenholt, K., 2002. Explaining learning curves for wind power. Energy Policy 30, 11811189.

Jakob, M., Madlener, R., 2004. Riding down the experience curve for energy-efficient building envelopes: The Swiss case for 1970-2020. International Journal of Energy Technology and Policy 2 (1-2), 153-178.

Jamasb, T., 2007. Technical change theory and learning curves: patterns of progress in electricity generation technologies. Energy Journal 28 (3), 51-72.

Jamasb, T., Köhler, J., 2008. Learning curves for energy technology and policy analysis: A critical assessment, in: Grubb, M., Jamasb, T., Pollitt, M.G. (Eds.), Delivering a low carbon electricity system: Technologies, economics and policy. Cambridge University Press, Cambridge, pp. 314-332.

Jardot, D., Eichhammer, W., Fleiter, T., 2009. Effects of economies of scale and experience on the costs of energy-efficient technologies - case study of electric motors. Proceedings of 2009 ECEEE Summer Study.

Joskow, P.L., Rozanski, G. A., 1979. The effects of learning by doing on nuclear plant operating reliability. Review of Economics and Statistics 61 (2), 161-168.

Junginger, M., Faaij, A., Turkenburg, W.C., 2005. Global experience curves for wind farms. Energy Policy 33, 133-150.

Klaassen, G., Miketa, A., Larsen, K., Sundqvist, T., 2005. The impact of R\&D on innovation for wind energy in Denmark, Germany and the United Kingdom. Ecological Economics 54 (2), 227-240.

Koh, H., Magee, C.L., 2006. A functional approach for studying technological progress: Application to information technology. Technological Forecasting and Social Change 73 (9), 10611083.

Koh, H., Magee, C.L., 2008. A functional approach for studying technological progress: Extension to energy technology. Technological Forecasting and Social Change 75 (6), 735758. 
Laitner, J.A., Sanstad, A.H., 2004. Learning-by-doing on both the demand and the supply sides: Implications for electric utility investments in a heuristic model. International Journal of Energy Technology and Policy 2 (1-2), 142-152.

Masini, A., Frankl, P., 2002. Forecasting the diffusion of photovoltaic systems in southern Europe: A learning curve approach. Technological Forecasting and Social Change 70, 39-65.

McDonald, A., Schrattenholzer, L., 2001. Learning rates for energy technologies. Energy Policy 29, 255-261.

Moore, G.E., 1965. Cramming More Components Onto Integrated Circuits. Electronics 38 (8), 114-117.

Neij, L., 1997. Use of experience curves to analyze the prospects for diffusion and adoption of renewable energy technology. Energy Policy 23, 1099-1107.

Neij, L., Andersen, P.D., Durstewitz, M., 2003. The use of experience curves for assessing energy policy programs. In: Proceedings of the EU/IEA Workshop on Experience Curves: A Tool for Energy Policy Analysis and Design, Paris.

Nemet, G.F., 2006. Beyond the learning curve: Factors influencing cost reductions in photovoltaics. Energy Policy 34, 3218-3232.

Newell, R.G., 2000. Incorporation of Technological Learning into NEMS Buildings Modules. US Department of Energy, Energy Information Administration, Washington, DC.

Papineau, M., 2006. An economic perspective on experience curves and dynamic economies in renewable energy technologies. Energy Policy 34, 422-432.

Rosenquist, G., McNeil, M., Iyer, M., Meyers, S., McMahon, J., 2006. Energy efficiency standards for equipment: Additional opportunities in the residential and commercial sectors. Energy Policy 34, 3257-3267.

Schiellerup, P., 2002. An examination of the effectiveness of the EU minimum standard on cold appliances: the British case. Energy Policy 30, 327333.

US Department of Energy, 1995. Technical Support Document: Energy Efficiency Standards for Consumer Products: Refrigerators, Refrigerator-Freezers, and Freezers (Final Rule). Washington, DC.

US Department of Energy, 1997. Technical Support Document for Energy Conservation Standards for Room Air Conditioners: Volume 2 Detailed Analysis of Efficiency Levels (Final Rule). Washington, DC.

US Department of Energy, 1999. Technical Support Document: Energy Efficiency Standards for Consumer Products: Residential Central Air Conditioners and Heat Pumps (Advanced Notice of Proposed Rulemaking). Washington, DC. 
US Department of Energy, 2007. Technical Support Document: Energy Efficiency Program for Consumer Products: Energy Conservation Standards for Residential Furnaces and Boilers (Final Rule). Washington, DC.

US Department of Energy, 2011a. Technical Support Document: Energy Efficiency Program for Consumer Products: Residential Clothes Dryers and Room Air Conditioner (Direct Final Rule). Washington, DC.

US Department of Energy, 2011b. Technical Support Document: Energy Efficiency Program for Consumer Products: Residential Central Air Conditioners, Heat Pumps, and Furnaces (Direct Final Rule). Washington, DC.

US Department of Energy, 2011c. Technical Support Document: Energy Efficiency Program for Consumer Products: Residential Refrigerators, Refrigerator-Freezers, and Freezers (Final Rule). Washington, DC.

van Benthem, A., Gillingham, K., Sweeney, J., 2008. Learning-by-doing and the optimal solar policy in California. The Energy Journal 29, 131-151.

van der Zwaan, B., Rabl, A., 2003. Prospects for PV: A learning curve analysis. Solar Energy 74, 19-31.

van Sark, W. G. J. H. M., 2008. Introducing errors in progress ratios determined from experience curves. Technological Forecasting and Social Change 75, 405-415.

Weiss, M., Junginger, M., Patel, M.K., Blok, K., 2010a. A review of experience curve analyses for energy demand technologies. Technological Forecasting and Social Change 77, 411-428.

Weiss, M., Patel, M.K., Junginger, M., Blok, K., 2010b. Analyzing price and efficiency dynamics of large appliances with the experience curve approach. Energy Policy 38, 770-783.

Wright, T.P., 1936. Factors affecting the cost of airplanes. Journal of Aeronautical Sciences $3,122-128$.

Yeh, S., Rubin, E., Hounshell, D.A., Taylor, M.R., 2009. Uncertainties in technology experience curves for integrated assessment models. Environmental Science and Technology 43 (18), 6907-6914.

Yelle, L. E., 1979. The learning curve: Historical review and comprehensive survey. Decision Science 10, 302-328.

Zimmerman, M. B., 1982. Learning effects and the commercialization of new energy technologies: The case of nuclear power. Bell Journal of Economics 13(2), 297-310. 